\title{
PROJETO MATERIAIS RECICLÁVEIS: UM RELATO DE PRÁTICA EM EDUCAÇÃO AMBIENTAL
}

\author{
Andressa Tornquist ${ }^{1}$ \\ Camila Becker ${ }^{2}$ \\ Jaqueline Simmianer ${ }^{3}$ \\ Luciana Preuss ${ }^{4}$
}

RESUMO: Procurando problematizar a temática "Lixo", conscientizando os alunos sobre sua ação no meio ambiente, a EMEF José de Anchieta aderiu ao projeto "Conscientização da destinação os materiais recicláveis", da empresa Revitare (Santa Cruz do Sul). Diversas atividades foram desenvolvidas: palestras, visitas a empresas, aulas teóricas e práticas, confecção de cartazes, painéis e peças de artesanato, recolhimento de material reciclável e troca por material esportivo e de limpeza. A culminância do projeto se fez através de um Seminário de Educação Ambiental, onde cada turma apresentou sua temática desenvolvida. A partir do seminário, um folder foi desenvolvido e distribuído a comunidade local.

Palavras-chave: Materiais Recicláveis; Educação Ambiental; Pedagogia de Projetos.

\section{INTRODUÇÃO}

Conforme os Parâmetros Curriculares Nacionais (BRASIL, 1998), a Educação Ambiental é o conjunto de temáticas relativas não só a proteção da vida no planeta mas também à melhoria do meio ambiente e da qualidade de vida das comunidades. Sua função é contribuir para a formação de cidadãos conscientes, aptos para decidirem e atuarem na realidade socioambiental de um modo comprometido com a vida, com o bem-estar de cada um e a sociedade.

${ }^{2}$ Licenciada em Matemática e Mestre em Tecnologias e Processos Industriais.

${ }^{3}$ Licenciada em História.

${ }^{4}$ Licenciada em Língua Portuguesa.

Revbea, Rio Grande, V. 8, N² 2:164-168, 2013. 
Para o desenvolvimento deste projeto dentro do conceito de Educação Ambiental citado acima, utilizamos os referenciais adotados por nossa escola em seu Projeto Político Pedagógico: Pedagogia de Projetos e Interdisciplinaridade.

Para Fernández (apud KONRATH; ALMEIDA, 2010), as reflexões sobre o estado atual do processo ensino-aprendizagem nos permitem identificar um movimento de ideias de diferentes correntes teóricas sobre a profundidade do binômio ensino e aprendizagem, entre as quais: concepções tradicionais, escolanovistas, tecnicistas e progressistas.

Para os autores (op. cit.), se analisarmos a situação atual da prática educativa em nossas escolas identificaremos problemas como: a grande ênfase dada a memorização, pouca preocupação com o desenvolvimento de habilidades para reflexão crítica e autocrítica dos conhecimentos que se aprende, entre outros.

A eficácia do processo ensino-aprendizagem está na resposta em que este dá à apropriação dos conhecimentos, ao desenvolvimento intelectual e físico do estudante, à formação de sentimentos, qualidades e valores, que alcancem os objetivos gerais e específicos propostos em cada nível de ensino, conduzindo a uma posição transformadora, que promova as ações coletivas, a solidariedade e o viver em comunidade.

A concepção de que o processo de ensino-aprendizagem é uma unidade dialética entre a instrução e a educação está associada à ideia de que igual característica existe entre ensinar e aprender. Esta relação remete a uma concepção de que o processo de ensino-aprendizagem tem uma estrutura e um funcionamento sistêmico, isto é, está composto por elementos estreitamente relacionados.

A partir destas considerações, trabalhou-se dentro da concepção teórica que vincula Pedagogia de Projetos e Interdisciplinaridade. A interdisciplinaridade é a integração de dois ou mais componentes curriculares na construção do conhecimento.

A Interdisciplinaridade está presente na educação desde que começou a ser aplicada na ciência. Sua função é superar a fragmentação do conhecimento, a falta de uma relação deste com a realidade do aluno e a fragmentação do conhecimento escolar, visto que, alegoricamente falando, a mente do aluno é parecida com um armário arquivo: abrem-se e fecham-se os arquivos conforme as aulas que lhe são dadas ${ }^{5}$.

Já a ideia de Pedagogia de Projetos foi criada no início do século passado por John Dewey. O autor tomou como base a concepção de que "educação é um processo de vida e não uma preparação para a vida futura". Ou seja, a escola deve representar o agora, a vida prática dos alunos, a

\footnotetext{
${ }^{5}$ (www.wikipedia.org, acesso out. 2010).
} 
sociedade de ele irão enfrentar em breve (www.wikipedia.org., acesso out. 2010).

Entendemos como Grellet, Signorelli e Scarpa (2001) que atualmente temos tanta informação que é difícil não mudar o contexto de aprendizagem. Ensinar é fazer aprender. Num projeto didático, trabalha-se com procedimentos, conceitos e atitudes como conteúdos de aprendizagem. Compartilha-se com os alunos uma aprendizagem com sentido. A escola costuma trabalhar conteúdos que não fazem sentido imediato para os alunos. Os projetos didáticos são uma evolução porque, além de tratar os conteúdos programados, eles contextualizam essas aprendizagens na busca de um produto final.

\section{ATIVIDADES DESENVOLVIDAS}

O projeto iniciou-se com uma palestra sobre Materiais Recicláveis, a cargo da empresa Revitare (de Santa Cruz do Sul - R. S.), a partir daí firmouse um convênio entre a empresa e a escola para a troca de materiais recicláveis por materiais diversos para a escola.

Aulas teóricas e práticas nas mais diversas áreas do saber envolveram a temática dos materiais recicláveis. Confeccionaram-se painéis e cartazes, além de peças de artesanato. Pesquisas diversas foram realizadas (O que é lixo? Quais os destinos do lixo? O que são materiais recicláveis? O que pode ser reciclado? Ciclo de alguns materiais recicláveis), assim como também um questionário foi desenvolvido junto aos alunos e comunidade, buscando dados sobre os tipos de resíduos produzidos e sua destinação final.

Como culminância realizou-se um "Seminário sobre Materiais Recicláveis" (Figura 1). A partir do seminário, um folder foi confeccionado e distribuído à comunidade (Figura 2), e cada turma de alunos apresentou suas pesquisas sobre 0 assunto(Figura 3).
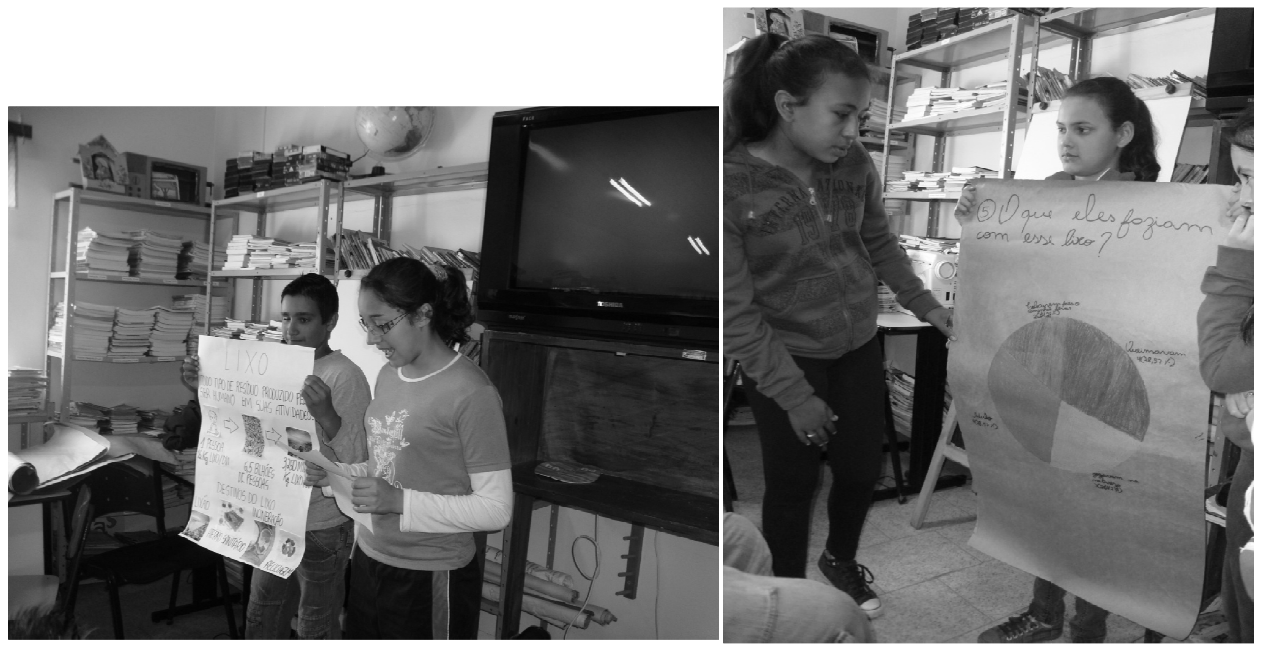

Figura 1: apresentações dos alunos durante o Seminário

Revbea, Rio Grande, V. 8, N² 2:164-168, 2013. 
É o lixo produridio nas lavouras das propriêdades rurais. E constituido principalmente, de matéria orgânicr. Seu thaior problema sđ̃o as antes de suz destow

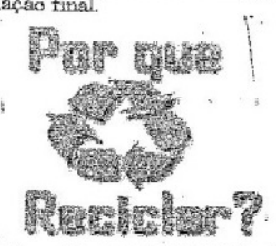

RECICLAGEM

A reciclagem é o processo que permite reaproveitar diverbos materiais que seriann destinados a lixîes ou aterros sariturios. Mas por que

Ao reciclar, poupamos đinheiros, pois para obter plástico, papel jeaproveitar o pue já existe:

Ao recicłar, economizamos energia, pois gasta-se raenos enexgia no reciclagèn do que ra obtençao a partir de fontes naturais;

Porque conservamos vários recursos naturais, como árvores, petroleo

* Ao reciciar diminuímos a quantidade de lixo, dimimuindo, tambérn, os
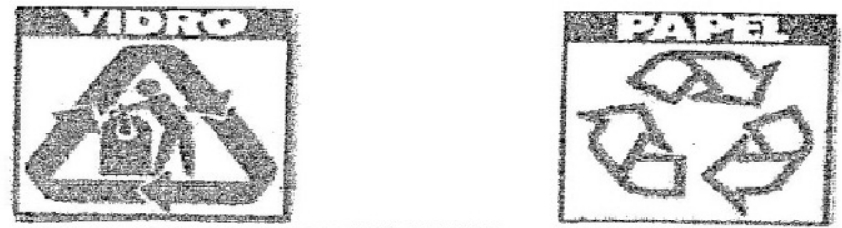

O QUE PODE SER RECICLADO?

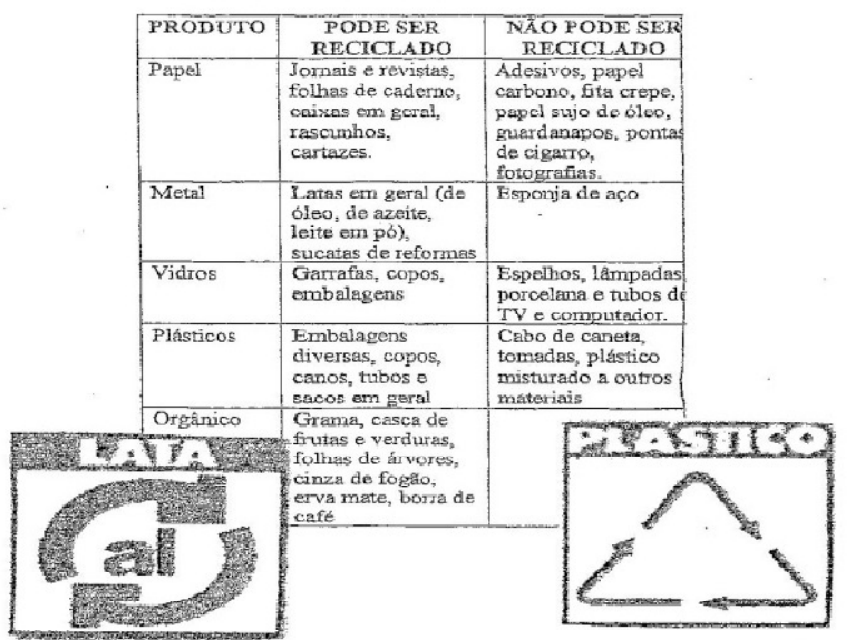

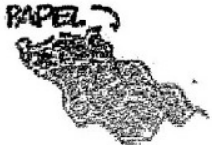
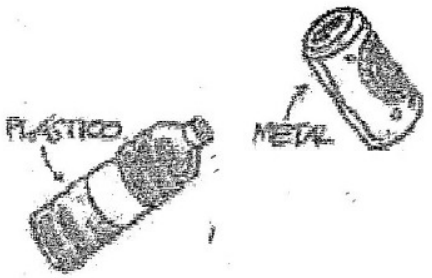

DURABILIDADE DOS MATERTAIS NA NATUREZA

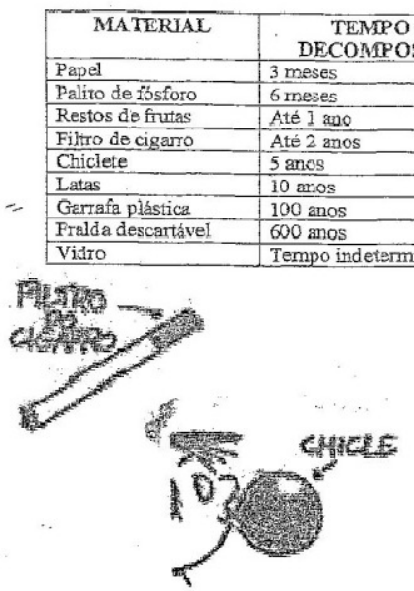

\section{CONCEITO DE LIXO}

Lixo é todo o residuo produzido peì homen nas aglomeraç̃os humanas: plásticos, papéis, embalagens, etc. Segundo as esiatisticas, cada pessoa. produz neio quilo de lixo dcméstico por dia. TIPOS DE LXXO

Lixo Urbano

É o lixo prcảuzido na casa das pessoas, restaurante encaminhado para aterros sanitários ou ixōes. É composto de sobras de papel, papelão, vidros, plásticos

\section{Liso Industrial}

É o lixo produzido pela indístria Em alguns casos poce ser perigoso destinaç̃o finsi.

Lixo Hospitalar
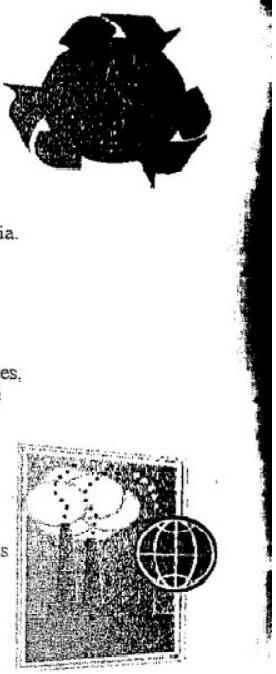

Y) O lixo hospitalar é um tipo de lixo especial que

requer um destino adequado, pois pode transmitir

doenças. Deve ser transportado em veículo especial

e disposto em local apropriado ou incinerado.

Figura 2: Folder confeccionado após o Seminário sobre Materiais Recicláveis

Revbea, Rio Grande, V. 8, N²:164-168, 2013. 


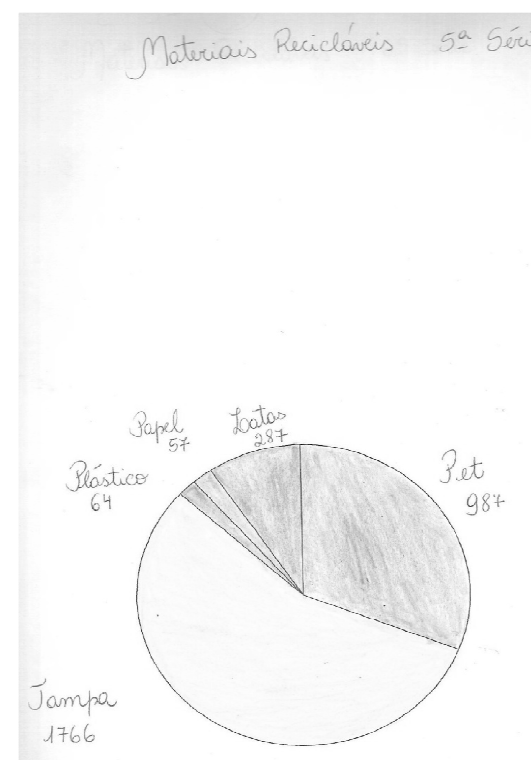

Figura 3: Gráfico com alguns dos dados obtidos através do questionário

\section{CONSIDERAÇÕES FINAIS}

Um grande problema socioambiental é o lixo. A produção de lixo é crescente, e nem sempre este tem o destino correto, o que causa malefícios a natureza. Percebeu-se que faltava à população local a conscientização quanto ao correto destino de seus resíduos.

Este projeto teve como foco os "Materiais Recicláveis" e através deles, a conscientização ambiental. A utilização deste tema gerador trouxe a população local, maior conhecimento sobre o assunto e conscientização quanto ao destino, separação e reutilização de resíduos.

A conscientização ambiental não extinguiu com ano de 2010, nem com a escrita deste trabalho. Trata-se de uma atividade contínua, cujos primeiros passos foram dados.

O "Projeto Materiais Recicláveis" é avaliado positivamente como ação pedagógica, já que possibilitou o trabalho interdisciplinar de um tema, tendo motivado os alunos no desempenho de suas atividades.

\section{REFERÊNCIAS}

BRASIL. Parâmetros Curriculares Nacionais. Brasília: MEC, 1998.

GRELLET, V.; SIGNORELLI, V.; SCARPA, R. Por que trabalhar com Projetos (Projetos Didáticos). Revista Nova Escola, № 146, outubro 2001.

KONRATH, M.; ALMEIDA, R. 0 processo de ensino-aprendizagem. Disponível em: http://cead.ufsm.br/moodle, out. 2010. Acesso restrito. 